\title{
Cryptococcus bacillisporus sp. nov.: Serotype B-C of Cryptococcus neoformans
}

\author{
K. J. KWON-CHUNG, ${ }^{1}$ JOHN E. BENNETT, ${ }^{1}$ AND THEODORE S. THEODORE ${ }^{2}$ \\ Laboratory of Clinical Investigation ${ }^{1}$ and Laboratory of Streptococcal Diseases, ${ }^{2}$ National Institute of \\ Allergy and Infectious Diseases, Bethesda, Maryland 20014
}

\begin{abstract}
Serotypes B and C of Cryptococcus neoformans are described as a separate species, $C$. bacillisporus sp. nov. $C$. bacillisporus could be distinguished from $C$. neoformans by creatinine metabolism. Serotype $\mathrm{B}$ and $\mathrm{C}$ isolates utilized creatinine much more readily than $A$ and $D$, resulting in increased ammonia production and alkaline pH. Based on these findings, a creatinine-dextrose-bromothymol blue agar medium (pH 5.7) was developed as a single-step culture method for separation of the two species. Isolates of $C$. neoformans can be distinguished from C. bacillisporus with $97 \%$ accuracy by $48 \mathrm{~h}$.
\end{abstract}

Cryptococcus neoformans has been regarded as a fairly homogeneous species except for the existence of serotypic variations among the isolates (3). In recent years, however, evidence of heterogeneity has become increasingly clear within the species. Kwon-Chung has shown that $C$. neoformans contains two perfect states, $\mathrm{Fi}$ lobasidiella neoformans and $F$. bacillispora $(5$, 6 ). Formation of the $F$. neoformans state was observed when crosses were made between the two mating types of serotype A or D isolates, whereas the $F$. bacillispora state was observed when similar crosses were made among serotype $\mathrm{B}$ or $\mathrm{C}$ isolates. Geographic differences have also been discovered in the distribution of the four serotypes. Whereas serotype $A$ is widespread throughout the world, $D$ was found to be rare in the United States but common in Europe. B and $C$ types are rare causes of infection except in Southern California (1). Also, the natural reservoir for the four serotypes seems to be distinct. Serotypes A and D were most commonly found in association with pigeon droppings, whereas the ecological niche of $B$ and $C$ still remains unknown. Biochemical differences among the four serotypes have also been noted. In our recent study (1a), it was demonstrated that $l$ malic acid is utilized as a sole source of carbon by serotypes $B$ and $C$ but not by $A$ and $D$. The difference in the assimilation pattern of $l$-malic acid is explained by a marked difference in uptake of the dicarboxylic acid between the two groups (1a). Additional differences were also noted between these two groups. Serotypes B and $\mathbf{C}$ commonly caused greening of Guizotia agar medium, but serotypes $A$ and $D$ did not. Although the mechanism of greening was not established, it was reported that alkaline $\mathrm{pH}$ caused greening of the medium (10). The production of ammonia by serotypes $B$ and $C$ has been suspected as the cause for the greening of the medium (1a). It was shown that creatinine is an essential component of the medium for the greening by the fungus, and the greened medium produced an ammonia-like odor. Alkalization of the medium with $\mathrm{NH}_{4} \mathrm{OH}$ caused immediate and stable greening.

The study to be reported here shows that creatinine consumption and ammonia formation by the two groups grown in creatinine dextrose medium differed significantly. On the basis of such findings, we have developed a simple, onestep technique for the differentiation of serotypes $A$ and D from B and C. For the purposes of this paper, serotype $B$ and $C$ isolates will be designated "B-C." Isolates of $A$ and $D$ serotype will be termed "A-D."

Based on the present study as well as genetic, biochemical, ecological, and antigenic differences, it is apparent that serotype A-D and B-C can be separated into two distinct species. The binomial $C$. neoformans should be used for the asexual state of $F$. neoformans (serotype A-D). The type strain of $C$. neoformans, CBS 132, which was assumed to be the original isolate of Sanfelice (7), was serotype D and produced fertile basidiospores when crossed with $a$ tester strains of $F$. neoformans.

This report includes the description of a new species for serotype B-C, differences in creatinine utilization and ammonia formation by the two species, and a simple technique for their differentiation.

\section{MATERIALS AND METHODS}

Isolates used for measurement of creatinine consumption and ammonia formation. Thirteen isolates of $C$. neoformans, clinical or natural origin, which were serotyped by the method described by Wilson et al. (13) were used. These included three 
isolates each of serotypes A, D, and B, and four isolates of serotype $C$. The inocula were grown on malt extract agar at $25^{\circ} \mathrm{C}$ for $24 \mathrm{~h}$, harvested in creatinine dextrose broth (see below), washed two times with the broth, adjusted to an optical density at $600 \mathrm{~nm}$ of 0.2 , and placed in ice until inoculation.

Medium for creatinine utilization and ammonia formation. Creatinine dextrose broth was prepared by dissolving the following in $1,000 \mathrm{ml}$ of distilled water: creatinine, $1 \mathrm{~g}$; dextrose, $1 \mathrm{~g}$; $\mathrm{MgSO}_{4} \cdot 7 \mathrm{H}_{2} \mathrm{O}, 0.5$ $\mathrm{g} ; \mathrm{KH}_{2} \mathrm{PO}_{4}, 1 \mathrm{~g} ; 1$ drop of thiamine-vitamin solution (Bejectal, Abbott Laboratories, North Chicago, Ill.). The $\mathrm{pH}$ was adjusted to 6 with $4 \mathrm{~N} \mathrm{NaOH}$, and the solution was filter sterilized. Inocula were used at 1:10 dilution in this medium to make 5 -ml cultures in 13.3$\mathrm{mm}$-ID tubes. Initial optical density values of these culture tubes ranged from 0.02 to 0.025 . Colony-forming units ranged from $1.2 \times 10^{6} / \mathrm{ml}$ to $3.2 \times 10^{6} / \mathrm{ml}$, depending on the isolates. Cultures were incubated at $34^{\circ} \mathrm{C}$ on a rotary drum at a speed of $2 \mathrm{rpm}$. Optical density and $\mathrm{pH}$ values were determined at 1,3 , and 6 days. Ammonia and creatinine assays were carried out with culture filtrates obtained by centrifugation and filter sterilization.

Ammonia assay. Ammonia present in culture fluids was determined by nesslerization after the release of ammonia by alkali (medium components present in culture fluids interfere with the direct analysis of ammonia with Nessler reagent). Culture fluid $(0.1$ to $0.5 \mathrm{ml})$ was placed in the outer well of a Conway diffusion dish, and $0.5 \mathrm{ml}$ of $1 \mathrm{~N} \mathrm{NaOH}$ was placed at another spot in the same well. The center well contained $0.4 \mathrm{ml}$ of $0.1 \mathrm{~N} \mathrm{H}_{2} \mathrm{SO}_{4}$. The dish was covered with a glass plate, and the sample was mixed with the alkali and incubated at $37^{\circ} \mathrm{C}$ for 6 to $8 \mathrm{~h}$. The ammonia was trapped in the acid and determined by nesslerization (11). The sample was quantitatively removed from the center well, reacted with $1.0 \mathrm{ml}$ of Nessler reagent and $1.5 \mathrm{ml}$ of $2 \mathrm{~N} \mathrm{NaOH}$, incubated at room temperature for $15 \mathrm{~min}$, and read at $490 \mathrm{~nm}$. Standard curves were done routinely using $\left(\mathrm{NH}_{4}\right)_{2} \mathrm{SO}_{4}$ as the standard.

Creatinine assay. Creatinine present in culture fluids was measured by the method described by Folin et al. (4). The diluted culture fluid was mixed with alkaline picrate in a 5:2 ratio, incubated at room temperature for $16 \mathrm{~min}$, and read at $520 \mathrm{~nm}$.

Statistical analysis. For comparison of $\mathrm{pH}$ change, creatinine consumption, and ammonia formation between serotypes A-D and B-C, mean values were compared by Student's $t$ test.

Single-step method for the differentiation of serotypes A-D and B-C. Creatinine-dextrose agar medium with a dye indicator (CDB), bromothymol blue, was developed as a diagnostic culture medium to distinguish serotype A-D from B-C. The medium contained the following: creatinine, $1 \mathrm{~g}$; dextrose, $0.5 \mathrm{~g}$; $\mathrm{KH}_{2} \mathrm{PO}_{4}, 1 \mathrm{~g} ; \mathrm{MgSO}_{4} \cdot 7 \mathrm{H}_{2} \mathrm{O}, 0.5 \mathrm{~g}$; thiamine (Bejectal) solution, 1 drop; agar (Difco), $20 \mathrm{~g}$; bromothymol blue solution, $20 \mathrm{ml}$; and distilled water, $980 \mathrm{ml}$. The stock solution of indicator was prepared by dissolving $0.4 \mathrm{~g}$ of bromothymol blue in $64 \mathrm{ml}$ of $0.01 \mathrm{~N} \mathrm{NaOH}$ and made up to a final volume of $100 \mathrm{ml}$ with distilled water. The stock dye solution was stable for at least 4 weeks at $25^{\circ} \mathrm{C}$. The $\mathrm{pH}$ of the medium after steriliza- tion varied from 5.9 to 6.0 and was adjusted to 5.7 with $4 \mathrm{~N} \mathrm{HCl}$. The color of the medium at $\mathrm{pH} 5.7$ was gold. A loopful of 2-day- or 2-week-old cultures grown on either malt extract agar or modified Sabouraud dextrose agar (2) was streaked on a slant or a plate of $\mathrm{CDB}$ and incubated at $25^{\circ} \mathrm{C}$ for 1 week. A total of 136 isolates (61 A, $4 \mathrm{AD}, 25 \mathrm{D}, 28 \mathrm{~B}$, and $18 \mathrm{C}$ types) were tested on this medium. All isolates were identified by previously published criteria (1a).

\section{RESULTS}

Growth rates on creatinine-dextrose medium. All isolates, except for two serotype A, showed a 10-fold increase in optical density after $24 \mathrm{~h}$ of incubation. The two isolates of serotype A required $72 \mathrm{~h}$ to reach the same increase of optical density. Growth ceased after $24 \mathrm{~h}$ except in the two slow-growing serotype A strains.

Creatinine consumption. The results (Fig. 1) show the concentration of creatinine remaining in the culture medium after 3 and 6 days of incubation. The concentration of creatinine found in the supernatant of A-D cultures differed significantly $(P<0.001)$ from the B-C group.

Ammonia formation and $\mathrm{pH}$. The concentration of ammonia present in the culture filtrate was inversely proportional to the concentration of creatinine remaining in the fluid. Isolates of serotype A-D produced much less ammonia than serotypes B-C $(P<0.001)$. The results in Fig. 2 show the comparative concentrations of ammonia present in the A-D and B-C culture filtrates at 3 and 6 days. The $\mathrm{pH}$ of the culture filtrate changed according to the amount of ammonia produced by the isolates (Fig. 3).

Results on the CDB differential medium. Color of CDB agar at pH 5.7 was gold. Isolates of serotype B-C changed the color of the agar around the colony to greenish blue before $24 \mathrm{~h}$,

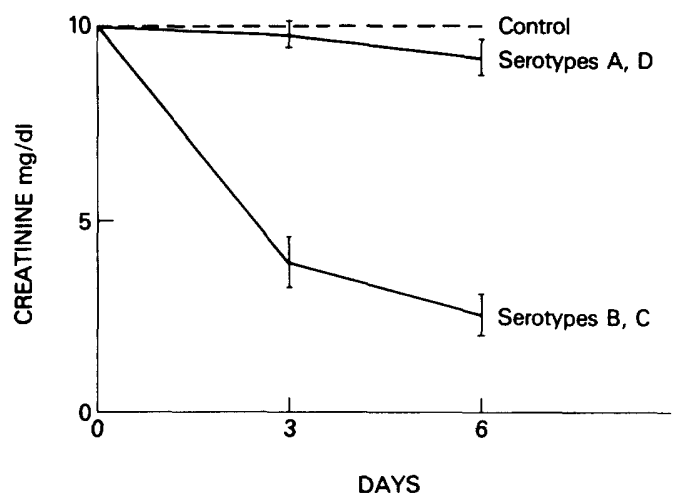

FIG. 1. Creatinine present in culture filtrates of six isolates of serotype A-D and seven isolates of serotype $B-C$ (standard error and mean value). 


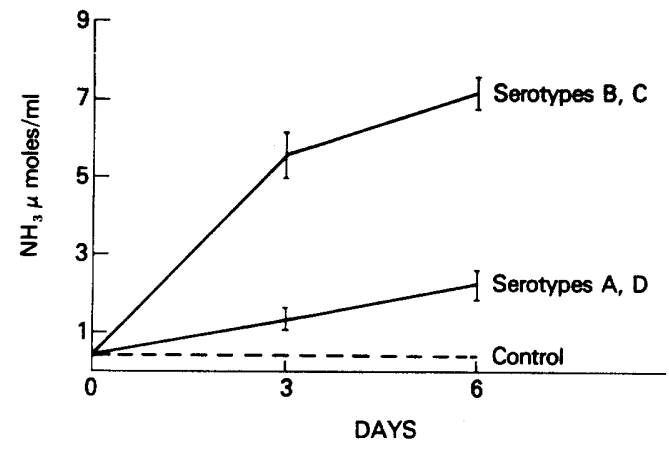

FIG. 2. Ammonia production by six isolates of serotype $A-D$ and seven isolates of serotype $B \cdot C$ in creatinine-dextrose broth.

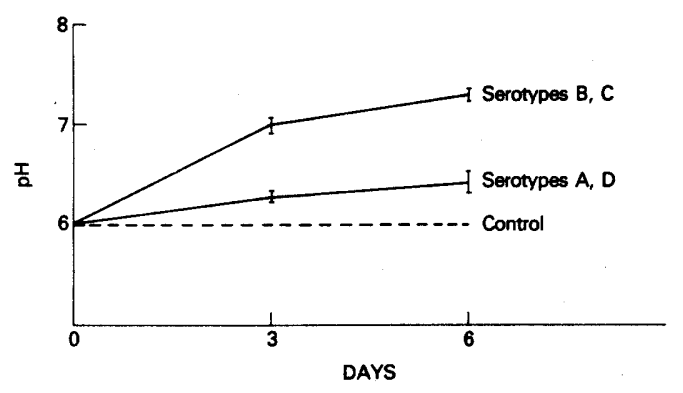

FIG. 3. $p H$ of culture fluids during 6 days of incubation by six isolates of serotype $A-D$ and seven isolates of serotype B-C in creatinine-dextrose broth.

except one isolate which produced the color change at $48 \mathrm{~h}$ (Table 1). Color of the agar plates or slants turned dark blue by 4 days with most $\mathrm{B}-\mathrm{C}$ isolates. All were dark blue by 7 days. The isolates of serotype A-D did not produce any color after $24 \mathrm{~h}$, but 4 of 90 isolates produced a green color at $48 \mathrm{~h}$, and these remained green or bluish green until the 7 th day. None of the 90 isolates turned the medium dark blue.

Since CDB agar did not allow differentiation of $C$. neoformans from other hyaline yeasts, chlorogenic acid (8), $0.36 \mathrm{~g} / \mathrm{liter}$, was added to the medium. Chlorogenic acid served as the substrate for phenoloxidase activity, a property unique to $C$. neoformans (8) regardless of serotype. The $\mathrm{pH}$ of the chlorogenic acid medium was more acidic than CDB agar and was adjusted to $\mathrm{pH} 5.7$ with $4 \mathrm{~N} \mathrm{NaOH}$. Most isolates produced brown colonies within $48 \mathrm{~h}$, and all did so by 4 days. Blue coloration of the medium started appearing after $24 \mathrm{~h}$ in most isolates of serotype $C$ and in a few isolates of serotype $B$. All isolates of serotype B-C produced blue within 4 days. Isolates of A-D produced no blue coloration within 4 days, and the four which produced green pigment on CDB agar showed light green color in $48 \mathrm{~h}$ and were still green at 7 days.

Description of the new species: Cryptococcus bacillisporus Kwon-Chung and Bennett sp. nov. Coloniae in extracto malti mucosae cremeaeque; cellulis globosis subglobosis ovalibus vel rare ellipticis, $2.5-7 \mu \mathrm{m}$ diam.; reproductio per gemmationem, mycelio et pseudomycelio carentibus; fermentatio negata; glucosum, galactosum, sucrosum, maltosum, cellobiosum (interdum leniter), trehalosum, raffinosum, L-arabinosum (varie), D-ribosum, Lrhamnosum, erithritolum (varie), ribitolum, galactitolum, D-mannitolum, acidum succicum, $l$ malicum (varie), citricum, et inositolum assimilata; lactosum non assimilatum; potassii nitritas nec nitris non assimilata; incrementum in agaro since substantiis "vitamin" dictis nullum, ad temperaturam $37^{\circ} \mathrm{C}$ certum; conformatio amyli certa vel debilis; morbum hominum et animalium excitans; habitatio naturalis ignota.

Status sexualis Filobasidiella bacillispora.

Cultura typica: ATCC 32608 (= CBS 6955), serotypus C.

Colonies on malt extract agar mucous and creamy, cells globose, subglobose, oval, and rarely elliptical, measuring 2.5 to $7 \mu \mathrm{m}$ in diameter, reproduce by budding, pseudo or true mycelium absent. Fermentation negative. Glucose, galactose, sucrose, maltose, cellobiose (occasionally weak), trehalose, raffinose, L-arabinose (variable), D-ribose, L-rhamnose, erithritol (variable), ribitol, galactitol, D-mannitol, succinic acid, $l$-malic acid (rarely latent), citric acid, and inositol assimilated, and lactose not assimilated. Potassium nitrate or nitrite not assimilated. Growth in vitamin-free medium absent. Growth at $37^{\circ} \mathrm{C}$ positive. Starch formation positive or weakly positive. Pathogenic to man and animal. Natural habitat unknown.

\begin{tabular}{|c|c|c|c|c|}
\hline \multirow{2}{*}{ Serotypes } & \multirow{2}{*}{$\begin{array}{l}\text { No. of } \\
\text { isolates }\end{array}$} & \multicolumn{3}{|c|}{ Color change } \\
\hline & & 24-h no. (\%) & \multicolumn{2}{|c|}{ 48-h no. (\%) } \\
\hline & 61 & 0 & $2^{a}$ & (3.3) \\
\hline & 25 & 0 & $2^{a}$ & (8.0) \\
\hline D & 4 & 0 & 0 & \\
\hline \multirow[t]{3}{*}{ Subtotal } & 90 & $(0)$ & 4 & (4.4) \\
\hline & 28 & $28(100)$ & 28 & (100) \\
\hline & 18 & $17(94.4)$ & 18 & (100) \\
\hline Subtotal & 46 & $45 \quad(97.8)$ & 46 & (100) \\
\hline
\end{tabular}

${ }^{a}$ Color is never blue but yellowish green. 
Sexual state: Filobasidiella bacillispora.

Type culture: ATCC 32608 (= CBS 6955), serotype $C$.

Isolates of $C$. bacillisporus can be differentiated from $C$. neoformans by the production of blue color on creatinine-dextrose-bromothymol blue agar medium within $48 \mathrm{~h}$. The specific epithet bacillisporus was selected to show correlation with the species epithet of the sexual state Filobasidiella bacillispora.

\section{DISCUSSION}

The present work was initiated to compare creatinine assimilation and formation of ammonia by isolates of serotype A-D (C. neoformans) and B-C (C. bacillisporus). The above results are compatible with the hypothesis that $C$. $b a$ cillisporus produces significantly more ammonia than C. neoformans and thus causes greening of Guizotia medium (1a). The nature of the color indicator in Guizotia medium has not been investigated. The $\mathrm{pH}$ difference due to the amount of ammonia formed by $C$. neoformans and $C$. bacillisporus was proven to be useful as a diagnostic tool for the two species. As a single-step method for their differentiation, bromothymol blue, $\mathrm{pH}$ range 6.0 to 7.6 , was selected as an indicator $(\mathrm{pH} \mathrm{7.0)}$ in the creatinine-dextrose agar medium. The medium stayed golden at $\mathrm{pH}$ 5.7, yellow at below 5.7, greenish yellow at $\mathrm{pH} 6$, green at $\mathrm{pH} 7$, and turned blue at $\mathrm{pH}$ above 7 . All of the 46 C. bacillisporus cultures turned the medium greenish blue within $48 \mathrm{~h}$, and dark blue by 4 to 7 days. Ninety-eight percent of $C$. bacillisporus could be correctly identified by $24 \mathrm{~h}$, and $100 \%$ could be correctly identified by $48 \mathrm{~h}$. The intensity of color varied among the isolates at $48 \mathrm{~h}$, but all of them turned the medium dark blue by 4 to 7 days. The inocula grown on either malt extract or modified Sabouraud agar for $\mathbf{4 8}$ $\mathrm{h}$ or 2 weeks showed similar results. However, the 48-h culture grown on the modified Sabouraud agar induced the color change slightly earlier, and the intensity was more consistent than those grown on malt extract agar. Of the 90 isolates of serotype A-D, 4 (4.4\%) produced green pigment within $48 \mathrm{~h}$ and remained green until 7 days. These false positive isolates did not assimilate $l$-malic acid within $48 \mathrm{~h}$ (1a), as did serotype $\mathrm{B}-\mathrm{C}$ isolates. The type culture of $C$. neoformans, CBS 132, produced neither green pigment nor assimilated $l$-malic acid within $48 \mathrm{~h}$. In our previous study (1a), two isolates of serotype $B$ lacking the perfect state did not assimilate $l$-malic acid within $48 \mathrm{~h}$. These isolates, however, gave a positive reaction on CDB medium within $48 \mathrm{~h}$ and formed a dark blue pigment after 4 days of incubation. These results indicated that $C$. neo- formans and $C$. bacillisporus can be distinguished within $48 \mathrm{~h}$ with $97 \%$ accuracy and with $100 \%$ accuracy by 7 days. The incorporation of chlorogenic acid into the differential medium should prove useful for the separation of the two species from other hyaline yeasts. A few isolates of $C$. laurentii also induced blue coloration on the chlorogenic acid CDB medium but lacked the brown-pigmented colony.

In comparison to the above-described method, the sexual cross for the identification of $C$. neoformans and C. bacillisporus is not practical. The difficulty is mainly due to instability of the mating reaction among isolates of $C$. bacillisporus. The type isolates and the tester strains of $F$. neoformans (serotype A-D) showed no evidence of loss of fertility for the past 2 years. The type isolates of $F$. bacillispora (serotype B-C), however, showed a drastic change during the same period. The formation of dikaryon and basidiospores was much more restricted and took a much longer period than when it was first described (6).

The biochemical pathways accounting for the success of CDB agar are unknown. Simple failure of serotype A-D isolates to utilize creatinine cannot explain the results because, under different conditions, serotype $D$ isolates utilized creatinine as a nitrogen source as well as serotype $\mathrm{B}$ or $\mathrm{C}$ and, in this system, even serotype A isolates utilized creatinine slowly (1a). The difference may lie in the ability of serotype B-C isolates to convert creatinine to urea, which is converted by urease into ammonia. This postulate is currently being tested.

Vanbreuseghem and Takashio (12) described C. neoformans var. gattii to accommodate an atypical isolate of $C$. neoformans which formed elongated cells, in addition to the round cells, within mouse brain. This characteristic was lost during subcultures in vitro. We obtained the isolate through the courtesy of Dr. Vanbreuseghem and found it to fit the physiological criteria of $C$. bacillisporus and to be serotype B. The isolate did not cross with tester strains of either $F$. neoformans or $F$. bacillispora. We have observed some oval or pyriform cells in the brains of mice injected with two single basidiospore isolates of $C$. bacillisporus. The elongation of the cells was not marked as that reported in C. neoformans var. gattii (12). It is unknown how general this phenomenon is among isolates of $C$. bacillisporus or if it is even confined to that species. No other isolates of $C$. neoformans var. gattii are known to us. It remains a moot point whether $C$. neoformans var. gattii should be considered a synonym of $C$. bacillisporus. In any case, priority of the name $C$. neoformans var. gattii would not apply in this case since it 
was used for a variety status (9). Furthermore, the type culture of $C$. bacillisporus does not produce elongated cells in mouse brain and should not be considered identical to $C$. neoformans var. gattii.

\section{ACKNOWLEDGMENT}

We are indebted to Edith Cash, Nineveh, N.Y., for her preparation of the Latin diagnosis and W. B. Hill and F. A. McNey for their technical assistance.

\section{REPRINT REQUESTS}

Address reprint requests to: Dr. K. J. Kwon-Chung, Laboratory of Clinical Investigation, National Institute of Allergy and Infectious Diseases, Bethesda, MD 20014.

\section{LTERATURE CITED}

1. Bennett, J. E., K. J. Kwon-Chung, and D. H. Howard. 1977. Epidemiologic differences among serotypes of Cryptococcus neoformans. Am. J. Epidemiol. 105:582-586.

1a. Bennett, J. E., K. J. Kwon-Chung, and T. S. Theodore. 1978. Biochemical differences between serotypes of Cryptococcus neoformans. Sabouraudia 16:167-174.

2. Emmons, C. W., C. H. Binford, J. P. Utz, and K. J. Kwon-Chung. 1977. In Medical mycology, 3rd ed, p. 535. Lea and Febiger, Philadelphia.

3. Evans, E. E. 1950. The antigenic composition of $C$. neoformans. J. Immunol. 64:423-430.
4. Folin, O., and H. Wu. 1919. A system of blood analysis. J. Biol. Chem. 38:81-110.

5. Kwon-Chung, K. J. 1975. A new genus Filobasidiella, the perfect state of Cryptococcus neoformans. Mycologia 67:1197-1200.

6. Kwon-Chung, K. J. 1976. A new species of Filobasidiella, the sexual state of Cryptococcus neoformans B and $C$ serotypes. Mycologia 68:942-946.

7. Phaff, H. J., and J. W. Fell. 1970. Cryptococcus Kutzing amend. Phaff et Spencer, p. 1088-1145. In J. Lodder (ed.), The yeasts, 2nd ed. North Holland Publishing Co., Amsterdam.

8. Shaw, C. E., and L. Kapica. 1972. Production of diagnostic pigment by phenoloxidase activity of Cryptococcus neoformans. Appl. Microbiol. 24:824-830.

9. Stafleu, F. A., et al. (ed.). 1972. International code of botanical nomenclature. Regnum Veg. 82:1-426.

10. Staib, F., and M. Senska. 1973. Brown pigmentation (brown colour effect, BCE) of Cryptococcus neoformans on Guizotia abyssinica-creatinine agar as dependent on the initial pH value. Zentralbl. Bakteriol. Parasitenkd. Infektionskr. Hyg. Abt. I Orig. Reihe A. 225:113-124.

11. Umbreit, W. W., R. H. Burris, and J. F. Stauffer. 1957. Manometric techniques, 3rd ed., p. 238. Burgess Publishing Co., Minneapolis.

12. Vanbreuseghem, $R$., and $M$. Takashio. 1970. An atypical strain of Cryptococcus neoformans (Sanfelice) Vuillemin 1894. II. Cryptococcus neoformans var. gattii var. nov. Ann. Soc. Belge Med. Trop. 50:695-702.

13. Wilson, D. E., J. E. Bennett, and J. W. Bailey. 1968. Serologic grouping of Cryptococcus neoformans. Proc. Soc. Exp. Biol. Med. 127:820-823. 